\title{
Caracterização do regime fluvial da bacia hidrográfica do rio Acre
}

\author{
Characterization of the fluvial regime of the Acre river basin \\ Caracterización del régimen fluvial de la cuenca hidrográfica del río Acre
}

Recebido: 07/12/2021 | Revisado: 11/12/2021 | Aceito: 14/12/2021 | Publicado: 21/12/2021

\author{
Daniela Silva Tamwing \\ ORCID: https://orcid.org/0000-0003-0855-7789 \\ Universidade Federal do Acre, Brasil \\ E-mail: eng.danitamwing@gmail.com \\ Carolina de Lima Accorsi Montefusco \\ ORCID: https://orcid.org/0000-0003-1495-2814 \\ Universidade Federal do Acre, Brasil \\ E-mail: carolaccorsi@ hotmail.com \\ Rodrigo Otávio Peréa Serrano \\ ORCID: https://orcid.org/0000-0002-7786-8305 \\ Universidade Federal do Acre, Brasil \\ E-mail: ropereas@gmail.com \\ Anderson Azevedo Mesquita \\ ORCID: https://orcid.org/0000-0003-0947-8070 \\ Universidade Federal do Acre, Brasil \\ E-mail: amgeoufac@hotmail.com \\ José Genivaldo do Vale Moreira \\ ORCID: https://orcid.org/0000-0002-2994-8482 \\ Universidade Federal do Acre, Brasil \\ E-mail: genivaldoufac@gmail.com
}

\begin{abstract}
Resumo
O regime fluvial de um rio representa a variação do volume de água durante um período, e é uma ferramenta essencial para o estudo da disponibilidade hídrica. Nesse sentido, este trabalho objetivou caracterizar o regime hídrico fluvial da bacia hidrográfica do rio Acre, considerando a dinâmica espaço-temporal a fim de estudar a sua disponibilidade hídrica. Foram identificas as vazões médias, máximas e mínimas anuais e mensais, obtidas através de tratamento estatístico dos dados fluviométricos de cinco estações ao longo do rio Acre, disponibilizados pela ANA (Agência Nacional de Água e Saneamento Básico). Verificou-se que o período de maior disponibilidade hídrica, para as séries históricas estudadas, ocorreu entre os meses de dezembro a abril, enquanto o período com menores vazões médias mensais ocorreram entre junho e setembro.
\end{abstract}

Palavras-chave: Regime fluvial; Rio Acre; Disponibilidade hídrica.

\begin{abstract}
The fluvial regime of a river represents the volume variation of the water during a period, being an essential tool for the study of water availability. In this sense, this study aimed to characterize the fluvial water regime of the Acre river basin, considering the space-time dynamics to study its water availability. The average, the maximum and minimum annual and monthly flows were identified, which were obtained through statistical treatment of the fluviometric data of five stations along the Acre river, made available by ANA (National Agency for Water and Basic Sanitation). It was verified that the period of highest water availability, for the historical series studied, occurred between December and April, while the period with lower average monthly flows occurred between June and September.
\end{abstract}

Keywords: River regime; Acre River; Water availability.

\section{Resumen}

El régimen fluvial de un río representa la variación del volumen de agua durante un período y es una herramienta fundamental para el estudio de la disponibilidad hídrica. En esa dirección, este estudio tuvo como objetivo caracterizar el régimen hídrico fluvial de la cuenca hidrográfica del río Acre, teniendo en cuenta la dinámica espaciotemporal para estudiar su disponibilidad hídrica. Se identificaron caudales promedios, máximos y mínimos, anuales y mensuales, obtenidos mediante el tratamiento estadístico de datos fluviales de cinco estaciones a lo largo del río Acre, puestos a disposición por ANA (Agência Nacional de Água e Saneamento Básico). Se verificó que el período de mayor disponibilidad hídrica, para las series históricas estudiadas, ocurrió entre los meses de diciembre y abril, mientras que el período con menor caudales mensuales promedio ocurrió entre junio y septiembre.

Palabras clave: Régimen fluvial; Río Acre; Disponibilidad hídrica. 


\section{Introdução}

No decorrer da história foi crescente, em diversidade e exigências, o uso da água, tornando-se essencial para à sobrevivência humana o aproveitamento e a conservação dos recursos hídricos. Isso reforça a necessidade de estudos hidrológicos a fim de subsidiar a gestão pública na concepção, planejamento, projeto, construção e operação de meios para o controle da quantidade e qualidade da água (Heller \& Pádua, 2010).

No contexto hidrológico, a vazão dos rios tem importante representatividade na gestão dos recursos hídricos, além de papel fundamental para a formação das cidades e de seu desenvolvimento cultural, econômico e social, sendo uma das principais fontes de captação para o abastecimento de água da população (Shiklomanov, 1998).

Considerando que o regime fluvial de um rio representa a variação do volume de água durante um período hidrológico (Tucci, 2012), o conhecimento e análise deste é uma importante base para estudos de balanço hídrico e estimativa do ciclo sazonal da vazão (Simon et al., 2013).

O regime fluvial de um rio está relacionado pela interação dos cursos de água com as características da bacia hidrográfica, a condição climática regional e global, além das ações antrópicas sobre o sistema fluvial (Tucci, 2002; Lima et al., 2015). Segundo Capozzoli et al. (2017), os tipos de chuvas e a qualidade da estação chuvosa tem papel fundamental no que se refere a recarga dos aquíferos, evidenciando forte relação entre precipitação e a vazão.

A obtenção do regime fluviométrico caracteriza a dinâmica espaço-temporal dos volumes de água nos rios através de dados diários, mensais e anuais de séries históricas das vazões, sendo possível identificar a média, máxima e mínima anual. Essas informações são basais para a tomada de decisão no âmbito do planejamento ambiental para o equilíbrio dos ecossistemas e a sustentabilidade dos recursos hídricos (Rocha \& Dos Santos, 2018).

Nesse sentido, é indiscutível a relevância do estudo hidrológico para a garantia da disponibilidade e a segurança hídrica das populações dependentes desses recursos. No entanto, ainda existem dificuldades quanto ao desenvolvimento de pesquisas nesta área, sobretudo em escala regional, como é o caso de algumas localidades da região amazônica. Isso se deve, em muitos casos, desde a carência de informações hidrológicas abrangentes à área de estudo até o apoio à realização de pesquisas voltadas a regiões específicas, mesmo que sejam menos complexas, mas que produzam resultados favoráveis à gestão.

No Brasil, a promulgação da Lei Federal n ${ }^{\circ}$ 9.433, de 08 de janeiro de 1997, foi um avanço, visto que o intuito é obter maior controle no uso da água no território nacional, estabelecendo a bacia hidrográfica como unidade de gestão, regulamentando assim os planos e estudos sobre recursos hídricos (Ana, 2021).

A partir da Lei das Águas, supracitada, os estados brasileiros passaram pelo processo de reflexão para a construção de uma política voltada à gestão dos recursos hídricos. Nesse contexto, o estado do Acre, no ano de 2012, elaborou o seu Plano Estadual de Recursos Hídricos (Acre, 2012), todavia, até o momento, não houve atualizações necessárias à continuidade do processo, regulamentado pela Lei Federal n 9433/97. Com isso, evidencia-se a necessidade de avanços no tocante a ações planejadas frente aos eventos hidrológicos extremos recentes, ao aumento progressivo das demandas hídricas em diversas áreas, ao efeito das ações antrópicas, além da deficiência de investimentos em projetos e operação de estruturas e sistemas hídricos inescusáveis.

Nesse sentido, o presente estudo visa caracterizar o regime fluvial do rio Acre, considerando a dinâmica espaçotemporal, no intento de embasar decisões quanto à disponibilidade hídrica da bacia hidrográfica.

O curso de água é utilizado de fonte de captação para o abastecimento de água tanto da capital Rio Branco quanto de outras cidades. O desígnio é obter informações das vazões máximas e mínimas mensais e anuais ao longo da série histórica dos dados das estações fluviométricas monitoradas pela Agência Nacional de Água e Saneamento Básico - ANA, as quais devem auxiliar na tomada de decisão para a gestão dos recursos hídricos presentes na região, bem como subsidiar novos estudos. 
Além do exposto, o estudo se justifica, sobretudo porque o regime hídrico da bacia do rio Acre se alterna mediante acentuado dinamismo sazonal. Historicamente, o estado do Acre e, principalmente a sua capital Rio Branco, tem uma problemática hidrológica caracterizada pela escassez de água no período seco, compreendido entre os meses de maio e setembro, conhecido por verão amazônico. Nesse período, é comum a potencialização dos problemas relacionados ao abastecimento de água. Por outro lado, apresenta um período notadamente chuvoso e de altos valores registrados de vazão, por vezes ocasionando inundações que acumulam severos danos à população, especialmente àqueles que habitam as áreas mais vulneráveis (Acre, 2012; Moreira \& Naghettini, 2016).

\section{Metodologia}

\section{1 Área de Estudo}

O estudo delimita-se à bacia hidrográfica do Rio Acre, que se situa na Amazônia Sul ocidental, compartilhada pelos estados brasileiros do Acre e Amazonas, pelo departamento peruano de Madre de Dios e pelo departamento boliviano de Pando, conforme se exibe na Figura 1 (Acre, 2012).

A bacia do Rio Acre apresenta uma rede hidrográfica formada por cursos de água volumosos e sinuosos, que escoam no sentido do Sudoeste para o Nordeste (Acre, 2012). Destacam-se cinco microbacias na bacia do rio Acre, sendo elas: Trinacional (Brasil, Peru, Bolívia), Biestadual (Acre, Amazonas), Xapuri, Riozinho do Rôla e Porto Acre (Duarte, 2011).

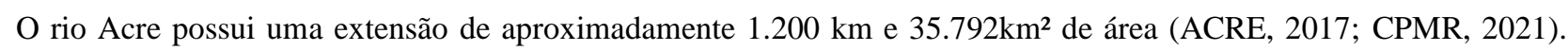
Tem um papel geopolítico importante no estado do Acre, atravessando os limites territoriais de dez municípios: Assis Brasil, Brasiléia, Epitaciolândia, Xapuri, Capixaba, Porto Acre, Rio Branco, Bujari, Sena Madureira e Senador Guiomard, abrangendo 1/5 da área total do Estado e mais de 60\% da população acreana (Acre, 2012; Duarte, 2011).

Referente ao regime de chuvas na bacia do rio Acre, tem como referência aproximadamente $1.900 \mathrm{~mm}$ de pluviosidade média anual, com período mais úmido e com tendência de ocorrência no mês de janeiro e período mais seco com tendência de ocorrência no mês de julho. Já o clima predominante na região é classificado, segundo Köppen, como equatorial quente e úmido (Acre, 2012; Silva et al., 2020). 
Figura 1. Mapa de Localização da Bacia Hidrográfica do rio Acre.

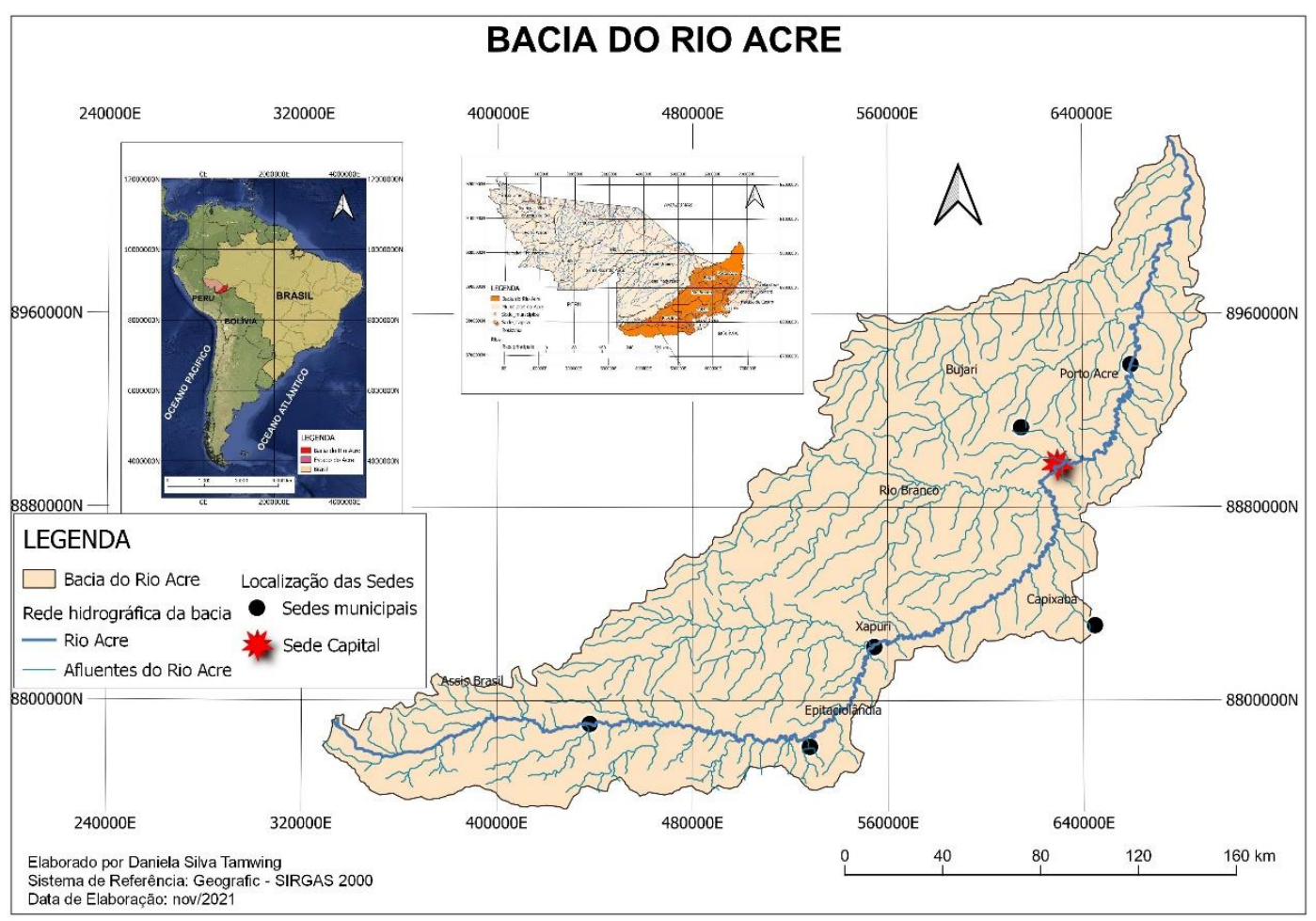

Fonte: Autores (2021).

\subsection{Obtenção dos dados}

As séries históricas de dados fluviométricos utilizados no presente trabalho foram obtidos no site da Agência Nacional de Águas e Saneamento Básico - ANA. Na base de dados da ANA é possível identificar vinte e cinco estações fluviométricas em operação na Bacia do rio Acre. Todavia, foram descartadas as estações com dados insuficientes para a análise estatística necessária nesta pesquisa.

Deste modo, esta pesquisa utilizou dados de vazão de cinco estações fluviométricas listadas na Tabela 1. Destaca-se que o município de Boca do Acre está localizado no estado do Amazonas, onde o rio Acre desagua na margem direta do rio Purus.

Tabela 1. Dados das Estações Fluviométricas na Bacia do rio Acre.

\begin{tabular}{c|c|c|c|c|c}
\hline Código & Município & Latitude & Longitude & $\begin{array}{c}\text { Área de } \\
\text { drenagem } \\
\left(\mathbf{k m}^{2}\right)\end{array}$ & $\begin{array}{c}\text { Período } \\
\text { analisado }\end{array}$ \\
\hline 13600002 & Rio Branco & $-9,975$ & $-67,8008$ & 23500 & $1967-2020$ \\
\hline 13470000 & Brasileia & $-11,0178$ & $-68,745$ & 7020 & $1982-2020$ \\
\hline 13550000 & Xapuri & $-10,6511$ & $-68,5075$ & 8270 & $1967-2020$ \\
\hline 13450000 & Assis Brasil & $-10,9436$ & $-69,5656$ & 3760 & $1983-2020$ \\
\hline 13650000 & Boca do Acre & $-9,0667$ & $-67,3969$ & 34400 & $1967-2020$ \\
\hline
\end{tabular}

Fonte: ANA. 
Adicionalmente, foram utilizados os dados históricos dos últimos censos realizados no munícipio de Rio BrancoAcre, disponibilizados pelo Instituto Brasileiro de Geografia e Estatística (IBGE), bem como informações hídricas fornecidas pelos órgãos municipais, estaduais e federais, entre outros.

\subsection{Tratamento estatístico}

Os dados foram submetidos ao crivo de diferentes ferramentas estatísticas, para fins de análise de comparação dos resultados obtidos. Primeiramente a uma verificação preliminar, com vistas a uma análise exploratória suficientemente capaz de levantar hipóteses ou sugerir tendências temporais.

Para caracterização do regime fluvial foram elaborados fluviogramas, que representam a variação de vazão em relação a um período, a fim de realizar análises estatísticas descritivas, tais como: medidas de posição, medidas de dispersão e variabilidade, análise de distribuição.

A rotina de cálculos foi executada a partir do pacote básico do Software Livre R-Project e do Microsoft Excel (R Core Team, 2020).

\section{Resultados e Discussão}

As ferramentas de estatística descritiva oportunizaram a obtenção da variação das vazões mínimas, máximas e médias para os registros fluviométricos das estações em estudo.

A Figura 2 apresenta as vazões mensais máximas e médias das Estações Fluviométricas nos municípios de Boca do Acre (Estação Floriano Peixoto), Brasileia, Xapuri, Rio Branco e Assis Brasil, respectivamente, onde é possível visualizar os períodos de maior disponibilidade hídrica ao longo do ano, ocasionadas pelo aumento da descarga. 
Figura 2. Gráficos das vazões mensais máximas e médias estações fluviométricas da bacia hidrográfica do rio Acre.
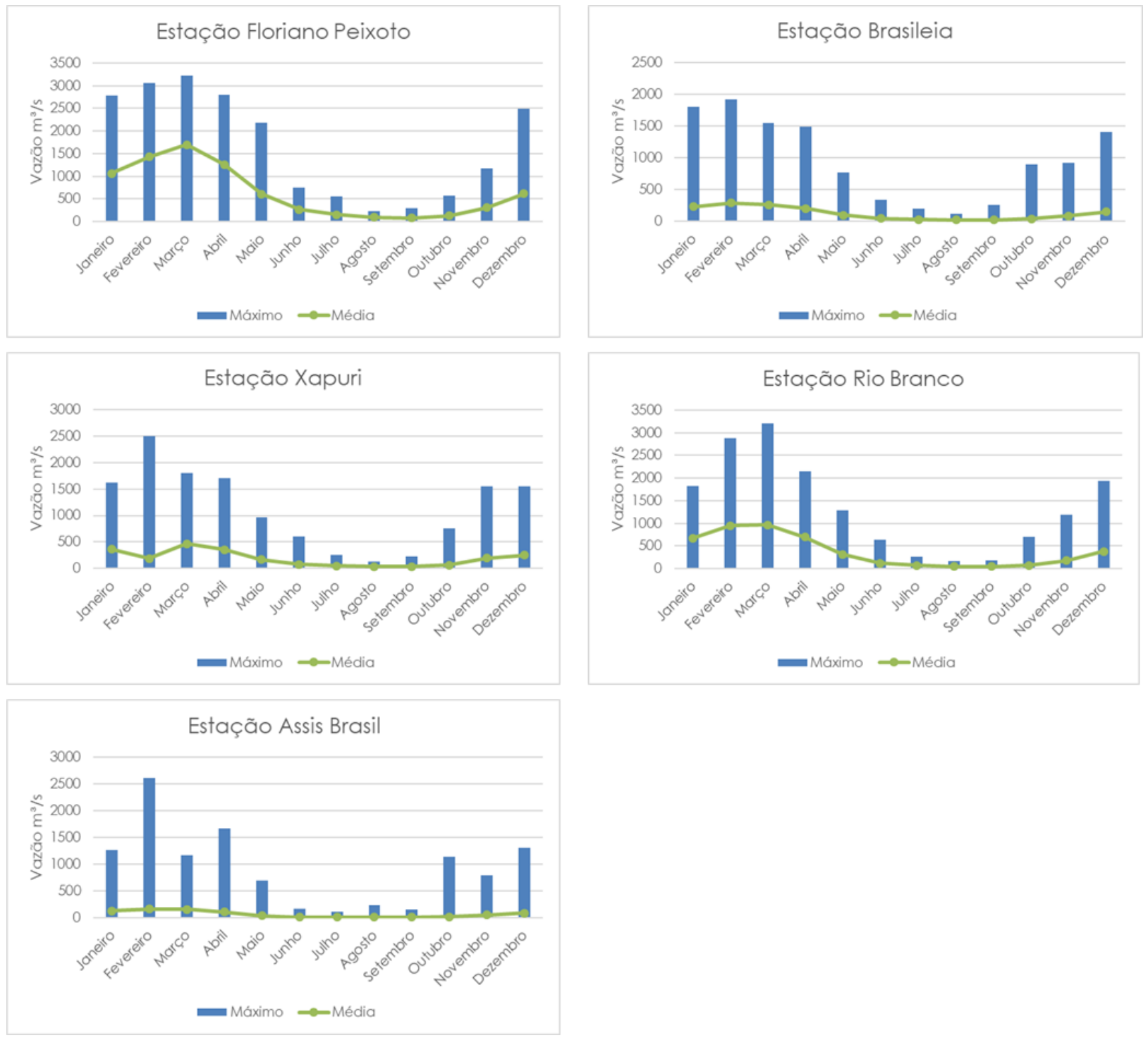

Fonte: Autores (2021).

A Estação de Floriano Peixoto, localizada no município de Boca do Acre, na fronteira do Amazonas com o Acre, apresenta as maiores vazões mensais médias e máximas dentre as estações estudadas. Essa é a estação mais à jusante entre as incluídas no presente estudo.

Quanto à distribuição mensal da disponibilidade hídrica, semelhantemente aos registros atinentes à cidade de Rio Branco, caracterizando-se o período entre os meses de dezembro a abril com os maiores valores de vazões, tendo como contraponto o período compreendido entre os meses de junho a outubro, com menores valores.

A Estação localizada no município de Assis Brasil apresenta regime fluviométrico que se destaca em relação às demais por apresentar as menores médias mensais, variando de 4,97 $\mathrm{m}^{3} / \mathrm{s}$, em setembro, a 162,32 $\mathrm{m}^{3} / \mathrm{s}$, em fevereiro. Isso é de razoável compreensão, uma vez que é a estação mais à montante entre as analisadas.

Em relação às vazões mínimas, a Figura 3 apresenta o fluviograma referente às estações analisadas. 
Figura 3. Fluviogramas das vazões mensais mínimas das estações fluviométricas da bacia hidrográfica do rio Acre.
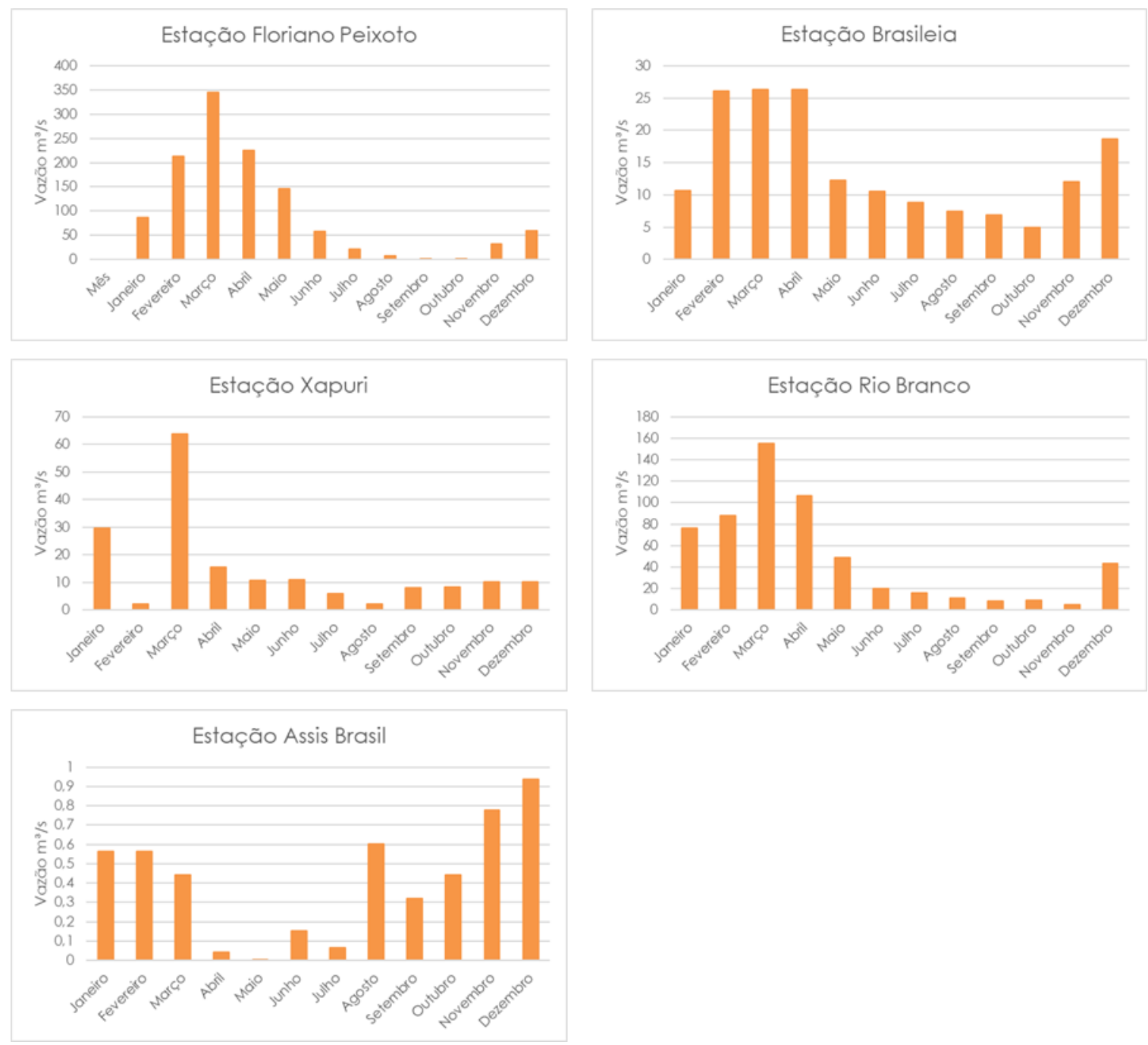

Fonte: Autores (2021).

A partir do fluviograma das vazões mensais mínimas (Figura 3), verifica-se a variabilidade de vazão ao longo do curso do rio Acre, onde se encontra a vazões mínimas menores na estação de Assis Brasil e as maiores na estação do município de Boca do Acre, denominada Floriano Peixoto, coincidindo o fluxo de nascente a foz. Em relação às vazões mínimas, também é possível verificar similaridade quanto à variabilidade mensal nas estações do município de Boca do Acre e Rio Branco.

De acordo com o fluviograma da vazões médias (Figura 2), na estação de Assis Brasil o período com menor disponibilidade hídrica é junho até setembro, mas destaca-se que no mês de maio ocorreu a menor vazão mínima (Figura 3), de 0,004 $\mathrm{m}^{3} / \mathrm{s}$, registrada no ano de 2005. Em contrapartida o período de cheias ocorreu entre dezembro e abril, com destaque para fevereiro que apresentou 162,32 m³/s, a maior média mensal (Figura 2).

Quando se analisa o fluviograma da estação de Xapuri (Figura 2 e 3), os meses de agosto e setembro tem a menor média mensal, com 38,85 m³/s e 38,59 m³/s, respectivamente. Ressalta-se, ainda, que o mês agosto registrou a vazão mínima mensal da série, com 2,22 m³/s no mês de agosto em 1985 .

Considerando-se as vazões médias, mínimas e máximas mensais da estação de Rio Branco, os meses com menor disponibilidade hídrica são julho, agosto, setembro e outubro. No entanto, também se verificou a ocorrência de anos em que a estiagem se prolonga até novembro, como o caso do ano 2010, que apresentou a vazão mínima mensal da série de 5,26m³/s em novembro, sendo a média deste mês no referido ano de $21,13 \mathrm{~m}^{3} / \mathrm{s}$. 
Na estação Floriano Peixoto, localizada em Boca do Acre, observa-se que as médias mensais apresentaram as mesmas características da estação de Rio Branco com as menores médias de vazões mensais nos meses entre julho e outubro.

No tocante aos registros temporais, a Figura 4 apresenta a série histórica referente às estações analisadas, contemplando os valores médios e mínimos das vazões, bem como o valor médio da série.

Figura 4. Série histórica para as vazões mínimas, médias e máximas na bacia hidrográfica do rio Acre.
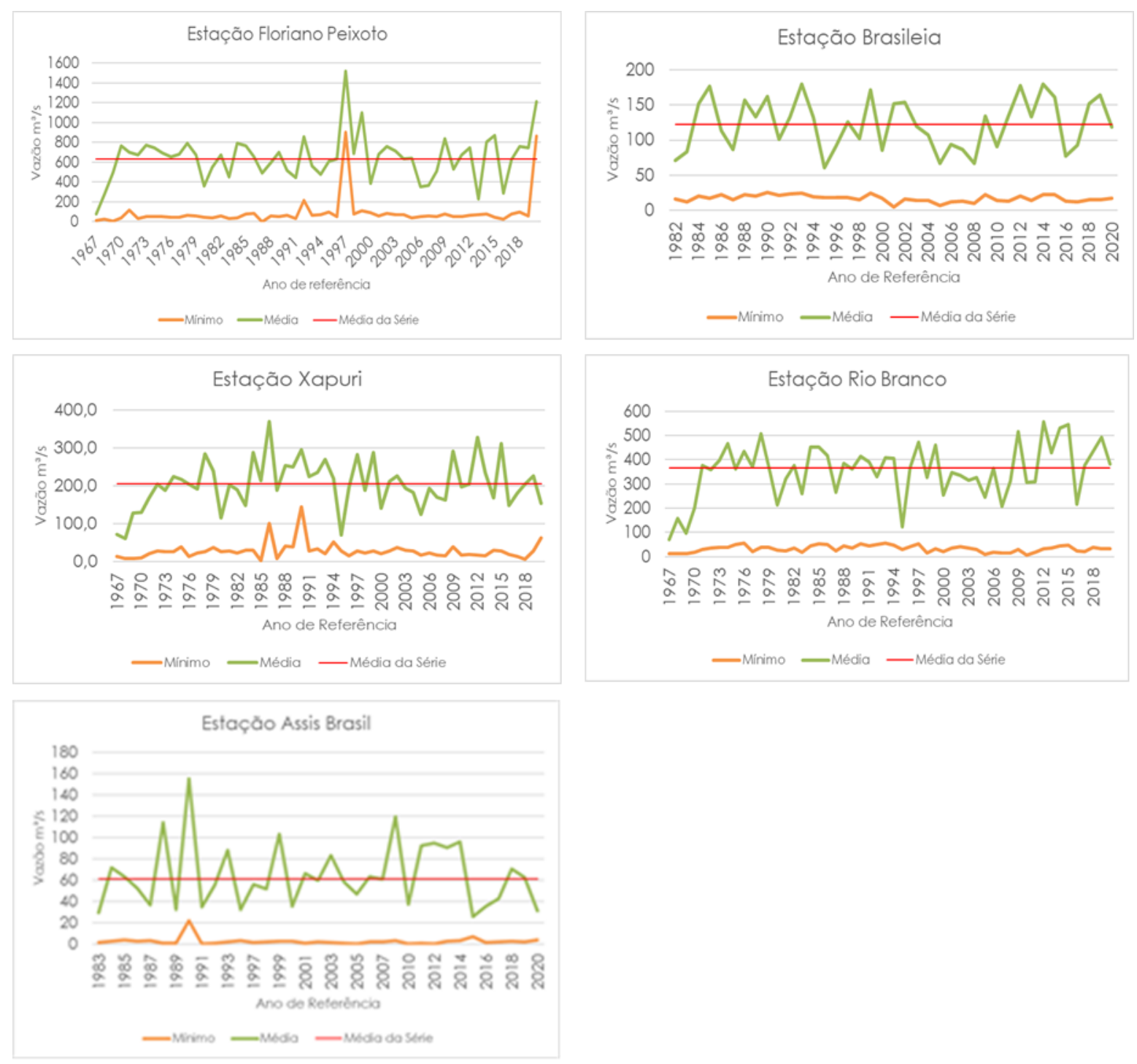

Fonte: Autores (2021).

Os resultados obtidos a partir das séries históricas da estação fluviométrica no município de Brasileia (Figura 4) apresentam vazão média anual de 122,67m³/s. Entre o período de 1982 e 2020 a vazão média anual varia de 61,03m³/s, registrado em 1995, a 179,47m³/s, registrado em 2014, o que demonstra a variação dados com desvio padrão de 36,21 m³.s.

O trecho do rio Acre localizado no município de Assis Brasil, apresenta uma vazão média anual de $61,06 \mathrm{~m}^{3} / \mathrm{s}$ na série histórica de 1983 a 2020 (Figura 4). Destaca-se que a menor média anual registrada ocorreu no ano de 2015, neste ano a vazão máxima foi de 189,65 m³/s ocorrida em dezembro e mínima de 7,08 m³/s nos meses de setembro e outubro.

Conforme apresentado na Figura 4, a menor vazão média encontrada na série histórica de 1967 a 2020 , da estação fluviométrica de Xapuri foi de $61,67 \mathrm{~m}^{3} / \mathrm{s}$ no ano de 1968. A vazão média anual da série foi de 206,41 m³/s, apresentando um desvio padrão de $63,38 \mathrm{~m}^{3} / \mathrm{s}$. 
Em Rio Branco, verificou-se vazão média anual 364,95 m³/s na série histórica de 1967 a 2020 (Figura 4), sendo a menor média anual de $71,77 \mathrm{~m}^{3} / \mathrm{s}$ registrada em 1967 , e maior média anual de $556,40 \mathrm{~m}^{3} / \mathrm{s}$. Isso demonstra a variação da série no decorrer dos anos das médias anuais, cujo desvio padrão desta série foi $110,36 \mathrm{~m}^{3} / \mathrm{s}$. Destaca-se que nas últimas duas décadas as vazões médias anuais não foram inferiores a $206,42 \mathrm{~m}^{3} / \mathrm{s}$.

As vazões médias anuais da estação Floriano Peixoto, no munícipio de Boca do Acre, na fronteira do Acre com o Amazonas, apresentaram variabilidade maior que as demais estações, com desvio padrão $234,47 \mathrm{~m}^{3} / \mathrm{s}$, o que pode ser observado quando se compara a média da série de $632,70 \mathrm{~m}^{3} / \mathrm{s}$, com a menor média anual de $76,7 \mathrm{~m}^{3} / \mathrm{s}$ em 1967 e a maior média anual de $1.518,23 \mathrm{~m}^{3} / \mathrm{s}$ em 1997.

Com os resultados obtidos, verifica-se que as vazões médias anuais das séries das estações fluviométricas, assim como das vazões mensais, variam ao longo do rio Acre, sendo a menor de $61,06 \mathrm{~m}^{3} / \mathrm{s}$ no município de Assis Brasil e maior de $632,70 \mathrm{~m}$ 3/s no município de Boca do Acre, o que coincide com o fluxo do rio da sua nascente até a foz.

Segundo Duarte (2011) pode-se relacionar a ocorrência ou falta de chuvas na bacia com o aumento ou diminuição do nível ou vazão do rio, a jusante. Desse modo, considerando o estudo de Sousa (2020), o mês que apresentou maior precipitação foi fevereiro, enquanto o que apresentou menor foi o de julho, relacionando esses resultados com obtidos nesse estudo verificase que o mês de fevereiro apresentou a segunda maior vazão média mensal e o mês de julho a terceira menor vazão média mensal.

A partir dos fluviogramas das vazões médias é possível diferenciar períodos de maior disponibilidade hídrica devido ao aumento da descarga líquida em todas as estações e os períodos de estiagem, ou seja, caracterizados por períodos de cheias e secas. De acordo com Sena et al. (2012), esses ciclos de enchentes e seca tem ocorrido de forma intensa da região Amazônica.

Essa característica de variabilidade da distribuição mensal da vazão também foi verificada em trabalhos sobre a bacia do rio Acre (Duarte, 2009; Duarte, 2011; CPMR, 2021; Accorsi et al., 2017). Macêdo et al. (2013) e Duarte (2011) apontam que a variabilidade climática interanual e a precipitação causam extremos de vazão dos cursos d'água, gerando uma vulnerabilidade social na população que reside nas áreas situadas nas planícies de inundação e o desabastecimento de água devido à escassez hídrica nos períodos de baixas vazões.

Nesse sentido, é importante destacar que, devido a sua abrangência territorial e populacional, a análise do rio Acre no trecho que envolve a capital acreana, Rio Branco, Buffon e Bonotto (2018) apontam que no ano de 2015 ocorreu a maior enchente da história do rio Acre, que superou a enchente ocorrida em 2012. O autor destaca, ainda, que em 2012 também ocorreu a seca mais severa até então, sendo superada apenas em 2016, quando o rio Acre chegou a nível mínimo registrado, apresentando nesse ano a vazão mínima de $24,92 \mathrm{~m} 3 / \mathrm{s}$.

A Figura 5 apresenta um fluviograma comparativo para as vazões registradas na cidade de Rio Branco, destacando os anos de 2012 e 2015. 
Figura 5. Fluviograma com as vazões médias dos anos (2012 e 2015) com ocorrências extremas (cheias e secas) no município de Rio Branco.

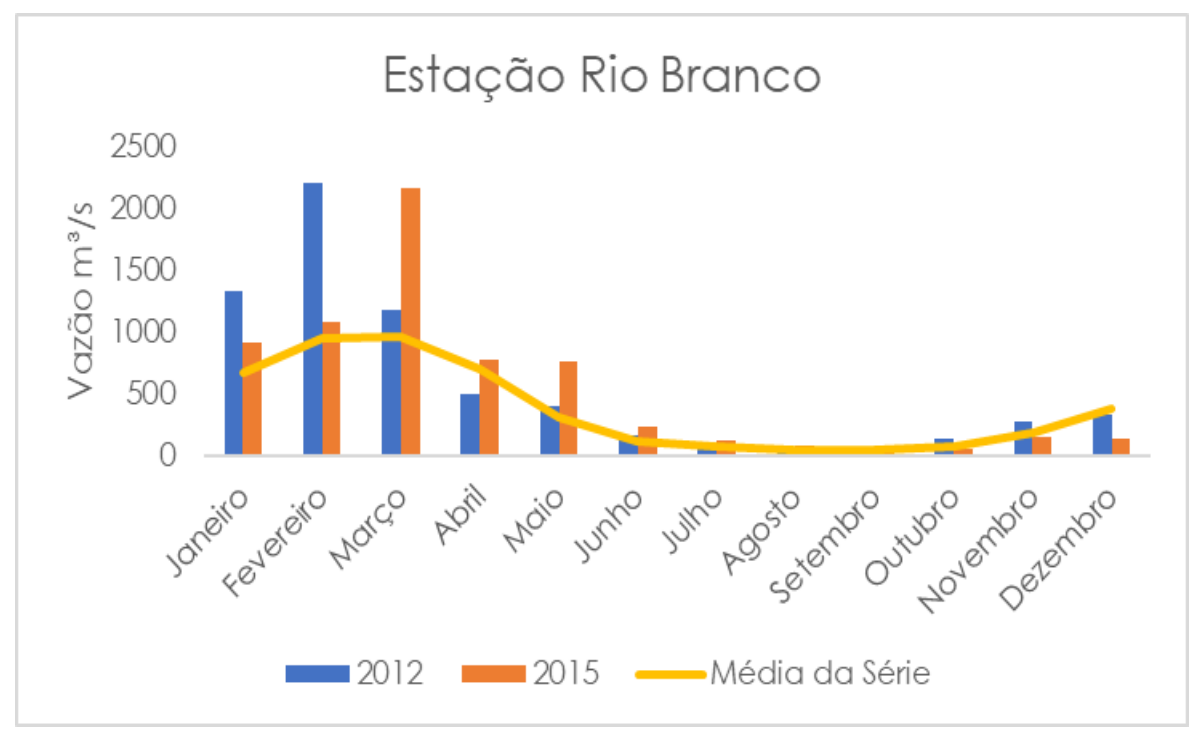

Fonte: Autores (2021).

A Figura 5 apresenta uma comparação entre os anos de 2012, com o segundo maior registro histórico de enchente e de seca no rio Acre, e o ano de 2015 com maior enchente (Buffon e Bonotto, 2018). Observa-se que eventos de enchente, acompanhados popularmente pela aferição das cotas do rio devido suas consequências desastrosas, também representam os extremos das vazões médias registradas. Em março de 2015 foi registrada a vazão máxima da série de 1967 a 2020 $\left(3.208,13 \mathrm{~m}^{3} / \mathrm{s}\right)$, enquanto a maior vazão média registrada na série ocorreu em 2012 , devido às vazões nos meses de janeiro e fevereiro terem sido consideravelmente superior do que 2015.

Duarte (2005) e Macêdo et al. (2013) destacam a necessidade de planejamento e gestão dos recursos hídricos frente aos impactos preocupantes das cheias e estiagens, considerando os prejuízos sociais, ambientais e financeiros.

Na Figura 6, apresenta-se um fluviograma das vazões mínimas dos anos de 2005 e 2010, que apresentaram as três menores vazões mínimas encontradas na série histórica estudada, a saber: 5,26 m³/s em novembro de $2010,8,49 \mathrm{~m} / \mathrm{s}$ em setembro de 2005, 9,20 m³/s em outubro de 2005. Para comparação foi acrescido o ano de 2016, quando ocorreu a maior seca registrada, com o nível do rio Acre chegando em 1,30 m (Buffon e Bonotto, 2018). 
Figura 6. Fluviograma das vazões mínimas nos anos de 2005, 2010 e 2017 da Estação Fluviométrica de Rio Branco.

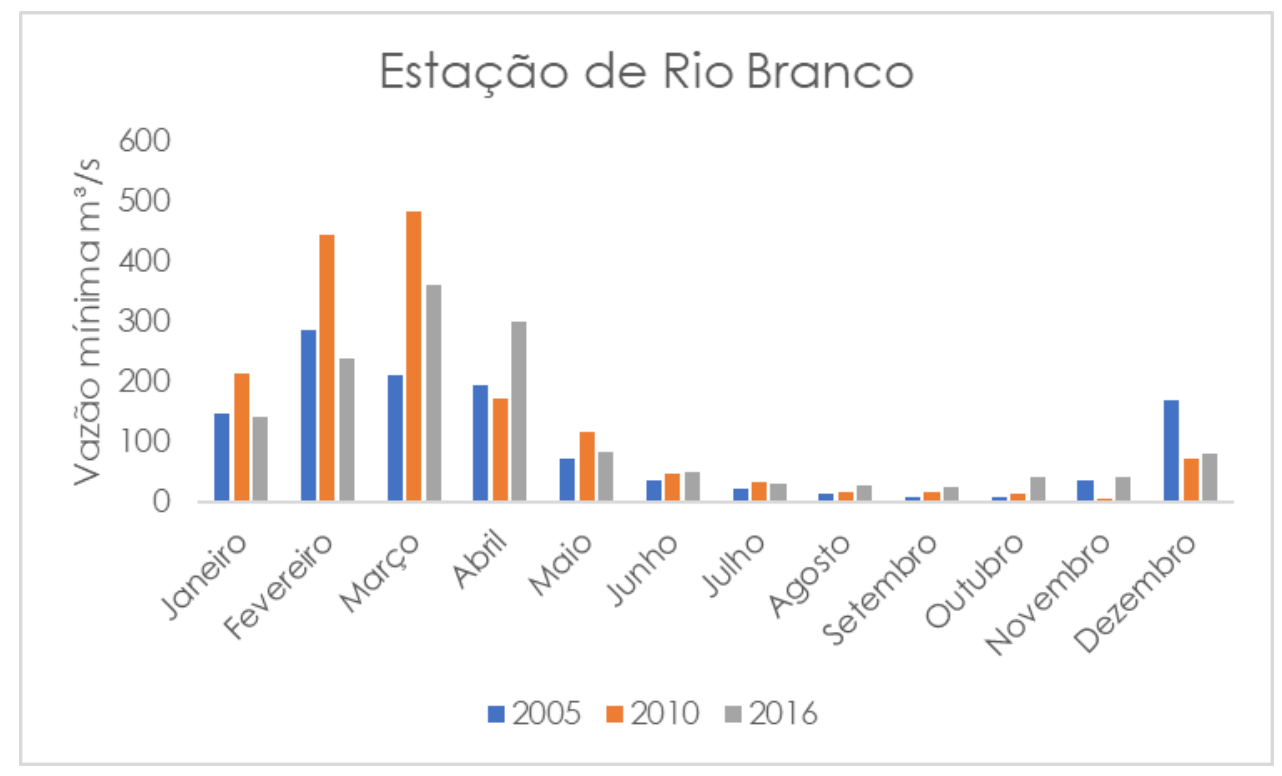

Fonte: Autores (2021).

A partir da análise da Figura 6, verifica-se que apesar do ano de 2016 ter ocorrido o nível mínimo histórico, as vazões mínimas no ano de 2005 ainda foram menores na maioria dos meses, com exceção para os meses de dezembro, janeiro e fevereiro. Apesar do menor nível registrado na história tenha ocorrido em setembro de 2016, neste mês foram registradas vazões mínimas menores nos anos de 2005 e 2010.

Segundo Parecer Técnico do Instituto Nacional de Meteorologia (2017), o evento extremo ocorrido em 2016, não foi um caso isolado, as condições meteorológicas atuantes nas regiões Norte e Nordeste do Brasil proporcionaram secas significativas naquele ano. De acordo os dados do Inmet (2017) o déficit acentuado de chuva envolvendo toda a região do Acre, somados a outros fatores como os efeitos do fenômeno El Niño e a ausência de episódios de Zona de Convergência do Atlântico Sul (ZCAS), contribuíram para a persistência do estado de alerta da baixa disponibilidade hídrica nos meses de julho, agosto e setembro e consequentes impactos socioambientais.

Nesse sentido, como consequência da seca extrema registrada em 2016, o Estado do Acre ficou em emergência devido ao risco eminente do colapso do abastecimento de água na capital. O Centro Nacional de Monitoramento e Alertas de Desastres Naturais, Cemaden (2016), destaca que além dos impactos na distribuição de água potável para a população, tiveram ainda como consequência a redução da produtividade agrícola ou pastoril, dificuldade de transporte hidroviário e proliferação de incêndios florestais, entre outros.

Duarte (2005) e Macêdo et al. (2013) ressaltam a preocupação referente a disponibilidade hídrica, considerando a redução gradual da capacidade de suprimento de água na bacia do rio Acre, que é principal fonte de abastecimento de água do Estado.

\section{Considerações Finais}

A partir dos resultados do presente estudo verificou-se que as estações ao longo do rio Acre apresentam, entre os meses de dezembro a abril, os maiores volumes de escoamento fluvial, sendo considerados como o período de maior disponibilidade hídrica na bacia devido ao aumento da descarga fluvial. Em contrapartida o período de menor disponibilidade hídrica, identificadas pelos meses de menores vazões médias mensais, compreende os meses de junho a setembro.

O acompanhamento da dinâmica espaço-temporal do regime fluvial do rio Acre são ferramentas indispensáveis para 
tomadas de decisões dos gestores públicos no âmbito do planejamento, manejo e gestão das bacias hidrográficas. Nesse sentido destaca-se a capital Rio Branco que historicamente vem sofrendo com eventos extremos de enchentes e secas que impactam negativamente a população.

Portanto, os resultados obtidos com o presente estudo servirão de subsídios a novas pesquisas na região em destaque, bem como de ferramentas de auxílio à decisão no que tange à gestão dos recursos hídricos.

\section{Agradecimentos}

Autores agradecem à Agência Nacional de Águas e Saneamento Básico (ANA) e à Universidade Federal do Acre (UFAC).

\section{Referências}

Accorsi O. J., Lima E. F. P., Alcoforado L. F., \& Longo O. C. (2017). Estudo do comportamento da cota mínima do rio Acre nos últimos 43 anos e as consequências para o assoreamento futuro do rio. Geociências, 36(2), 315-324.

ACRE. Secretaria de Estado de Meio Ambiente (2012). Plano estadual de recursos hídricos do Acre. Rio Branco: SEMA.

ACRE. Secretaria de Estado de Planejamento (2017). Acre em números. SEPLAN.

ANA - Agência Nacional de Águas e Saneamento Básico (2021). Política Nacional de Recursos Hídricos. Recuperado em 2 de setembro, 2021, de https://www.gov.br/ana/pt-br/assuntos/gestao-das-aguas/politica-nacional-de-recursos-hidricos

Buffon, F. T. \& Bonotto G. (2018). Ferramentas de apoio na operação do sistema de alerta da bacia do rio acre do serviço geológico do Brasil $S G B / C P R M$. I Encontro Nacional de Desastres.

Capozzoli C. R., Cardoso A. O., \& Ferraz S. E. T. (2017). Padrões de Variabilidade de Vazão de Rios nas Principais Bacias Brasileiras e Associação com Índices Climáticos. Revista Brasileira de Meteorologia, 32(2), 243-254.

CEMADEM - Centro Nacional de Monitoramento e Alertas de Desastres Naturais (2016). Panorama hídrico no estado do Acre: diagnóstico, perspectivas e impactos potenciais relacionados à situação de seca. Recuperado em 5 de outubro, 2021, de http://www2.cemaden.gov.br/wpcontent/uploads/2016/08/NT.Cemaden.SecaAcre.10082016.pdf.

CPMR - Serviço Geológico do Brasil. (2021). Bacia do Rio Acre-Características. https://www.cprm.gov.br/sace/acre_caracteristicas.php

Duarte, A. F. (2011). As chuvas e as vazões na bacia hidrográfica do rio Acre, Amazônia Ocidental: Caracterização e implicações socioeconômicas e ambientais. Amazônia: Ciência \& Desenvolvimento, 6(12), 161-183.

Duarte, A. F. (2009). Hidrometria no Acre: fluviometria e hidroquímica. Rio Branco: EDUFAC.

Duarte, A. F. (2005). Variabilidade e tendência das chuvas em Rio Branco, Acre, Brasil. Revista Brasileira de Meteorologia, $20(1), 37-42$.

Heller, L. \& Padua, V. L. (2010). Abastecimento de Água para Consumo Humano. Belo Horizonte: Editora UFMG.

INMET - Instituto Nacional de Meteorologia. (2017). Situação da seca observada nas regiões norte e nordeste do brasil em 2016 . Recuperado em 12 de novembro, 2021, de https://portal.inmet.gov.br/uploads/notastecnicas/trabalho_tecnico_02-2017.pdf.

Lima, J. E. F. W., Montenegro, S., De Assunção Montenegro, A. A., \& Koide, S. (2015). Comparative hydrology: relationships among physical characteristics, hydrological behavior, and results of the SWAT model in different regions of Brazil. Revista Brasileira de Geografia Física, 7(6), 1187-1195.

Macêdo, M. N. C., Dias, H. C. T., Coelho, F. M. G., Araújo, E. A., Souza, M. L. H., \& Silva, E. (2013). Precipitação pluviométrica e vazão da bacia hidrográfica do Riozinho do Rôla, Amazônia Ocidental. Ambiente \& Água, 8(1), 206-221.

Moreira, J. G. V. \& Naghettini, M. (2016). Detecção de tendências monotônicas temporais e relação como os erros dos tipos I e II: Estudo de caso em series de precipitações máximas anuais no estado do Acre. Revista Brasileira de Meteorologia, 31(4), 394-402.

Rocha, P. C. \& Dos Santos, A. A. (2018). Hydrological analysis in water basins. Mercator, 17, 1-18.

R CORE TEAM. (2020). R: A language and environmental for statistical computing. R Foundation for Statistical Computing, Vienna, Austria.

Sena, J., Beser De Deus, L., Freitas, M., \& Costa, L. (2012). Extreme events of droughts and floods in Amazonia: 2005 and 2009. Water Resources Management, 26(6), 1665-1676.

Shiklomanov, I.A. (1998). World water resource: a new appraisal and assessment for the $21^{\text {st }}$ century. UNESCO.

Silva J. R. S., Mesquita, A. A., Serrano R. O. P., \& Moreira J. G. V. (2020). Produtividade de mandioca na mesorregião Vale do Juruá, Acre, Brasil. Enciclopédia Biosfera, 17(33), 381-391. 
Research, Society and Development, v. 10, n. 17, e93101724461, 2021

(CC BY 4.0) | ISSN 2525-3409 | DOI: http://dx.doi.org/10.33448/rsd-v10i17.24461

Simon, F. W., Pickbrenner K., \& Marcuzzo F. F. N. (2013). Estudo do regime hídrico pluvial e fluvial em bacia hidrográfica com precipitação homogênea. XX Simpósio Brasileiro de Recursos Hídricos.

Sousa J. W. (2020). Características climáticas do município de Rio Branco, Acre, período de 1990-2019. Scientia Naturalis, 2(2), 723-740.

Tucci, C. E. M. (2012). Hidrologia: ciência e aplicação, Editora UFRGS.

Tucci, C. E. M. (2002). Regionalização de vazões. Editora UFRGS. 